\title{
CORRIGENDUM
}

\section{Comorbidities and continuities as ontogenic processes: Toward a developmental spectrum model of externalizing psychopathology-CORRIGENDUM}

THEODORE P. BEAUCHAINE AND TIFFANY MCNULTY

Ohio State University

doi:10.1017/S0954579413000746, published by Cambridge University Press, 17 December 2013

A secondary heading on page 1511 of our original article was incorrect. Heterotypic should have been homotypic in the heading Interim summary: Homotypic comorbidity of exter-

\section{Reference}

Beauchaine, T. P., \& McNulty, T. (2013). Comorbidities and continuities as ontogenic processes: Toward a developmental spectrum model of exter- nalizing syndromes. We regret this error and any problems it may have caused.

nalizing psychopathology. Development and Psychopathology, 24, $1505-1528$. 